DOI: $10.5185 /$ amlett.2017/11001

www.vbripress.com/aml

\title{
Healthcare Materials \& Medical Technology Conference
}

Dear Readers,

International Association of Advanced Materials (IAAM, www.iaamonline.org) is pleased to announce Healthcare Materials \& Medical Technology Conference 2018, Singapore with collaboration of VBRI Press AB, Sweden (www.vbripress.com). The conference aims to provide a forum to promote scientific exchanges in the field of healthcare materials \& medical technology including fundamental understandings, synthesis, characterisations and technological developments, discuss the most recent innovations and to foster global networks and collaborative ties between leading international researchers across various disciplines from medical, clinical, digital health, drug delivery, nanomedicine and clinical devices.

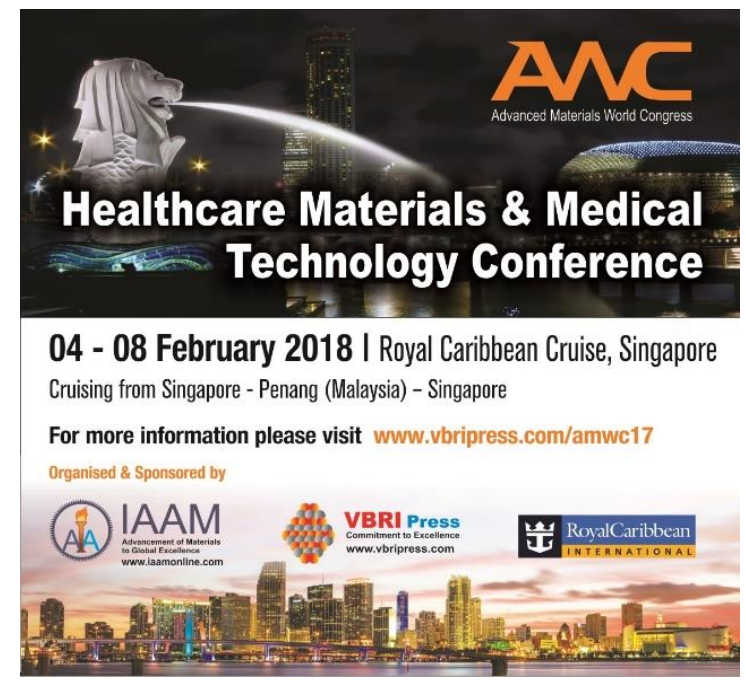

Fig. 1. Leaflet of Healthcare Materials \& Medical Technology Conference 2018, Singapore.

Call for abstracts is open in the Healthcare Materials \& Medical Technology Conference 2018, which is going to organize on the "Mariner of the Seas" cruising from Singapore - Penang (Malaysia) - Singapore during 04 - 08 February 2018. The organizers invite you to submit your abstracts through online abstract submission system and please encourage your collaborators/ colleagues/ students/ institute/ University to submit their abstracts by due date. Be part of "The World of Healthcare Materials \& Medical Technology". 500+ Delegates from 80+ Countries meeting in 30+ Sessions, Symposiums \& Exhibition.

Click here to Submit Abstracts in the Healthcare Materials \& Medical Technology Conference, Singapore. Please read Call for Abstracts and download abstract template, Healthcare Materials \& Medical Technology Conference, Singapore.

\section{Special attractions}

- Excellent speakers from industry and academia. It is a series of advanced materials cruise event where $10+$ international symposiums are hosted in the single vessel. We explore interdisciplinary connections with areas of healthcare materials \& medical technology.

- There is chance to visit two countries.

- Access to all parallel events in a single registration fee.

- The Advanced Materials Award, IAAM Medal Awards, IAAM Scientist Medal Awards, and Young Scientist awards will be privileged by the International Association of Advanced Materials.

- Amazing experience of cruising on the Strait of Malacca and enjoy sunny warm days and beautiful sea view.

\section{Highlights of activities}

- Excellent Speakers

- Interdisciplinary Research Presentations

- Global Networking

- Strong Attendance from Industry and Academia

- Parallel Symposiums

- Industry Exhibition

- Training Courses

- IAAM Awards and Felicitation

- Amazing Experience of Cruise Hospitality

- Explore two of the Countries

- Global Market

- Product Launches

For more information about conference, please visit http://www.vbripress.com/amwc17/pages/asian-Healthcarematerials-and-technology-conference and watch Advanced Materials Congress on YouTube Chanel

Look forward to meeting with you!

With best regards

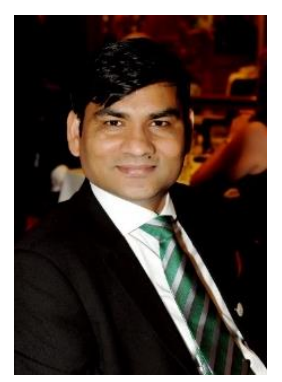

Ashutosh Tiwari, PhD, DSC

Editor-in-Chief

Advanced Materials Letters 